\title{
Wnt 2 contributes to the progression of gastric cancer by promoting cell migration and invasion
}

\author{
ZHAORAN ZHANG $^{1^{*}}$, JINYAN WANG $^{2 *}$ and XIANG DONG ${ }^{1}$ \\ ${ }^{1}$ Department of Gastroenterology, Jining First People's Hospital, Jining, Shandong 272000; \\ ${ }^{2}$ Department of Gastroenterology, Liaocheng People's Hospital, Liaocheng, Shandong 252000, P.R. China
}

Received September 7, 2016; Accepted April 18, 2018

DOI: $10.3892 / \mathrm{ol} .2018 .9050$

\begin{abstract}
Wnt2 plays a pivotal role in human cancer. However, it is not yet known whether Wnt2 contributes to promoting migration and invasion of gastric cancer. The present study aimed to investigate the expression of Wnt 2 in gastric cancer tissues and cell lines, and to analyze the effect of Wnt 2 on gastric cancer cells. Wnt2 expression level was evaluated in gastric cancer samples and adjacent normal gastric tissues by immunohistochemical and western blot analysis. To investigate the effect of Wnt 2 on gastric cancer cells, an in vitro Wnt 2 secreting system was established using $\mathrm{CHO}$ cells. The results indicated that Wnt2 is overexpressed in gastric cancer and is implicated in metastasis and TNM stage. Additionally, the results of in vitro experiments demonstrated that Wnt2 contributes to enhancing the migration and invasion abilities of gastric cancer cells. These results suggested that Wnt2 may be an effective target of treatment for patients with advanced gastric cancer.
\end{abstract}

\section{Introduction}

Gastric cancer is one of the most common lethal malignancies and the second leading cause of cancer-associated cases of mortality worldwide (1). Gastric cancer was the second leading cause of cancer mortality in China, with an estimated 297,496 cases of mortality in 2011 (2). Gastric cancer is often diagnosed at an advanced stage, and the 5-year survival rate of patients with gastric cancer remains low (3). There is an urgent need to improve prevention of gastric cancer and identify novel diagnostic methods and therapeutic treatments. However, the molecular pathogenesis of progression in gastric cancer remains unclear. It is therefore necessary to identify

Correspondence to: Dr Xiang Dong, Department of Gastroenterology, Jining First People's Hospital, 6 Jianking Road, Jining, Shandong 272000, P.R. China

E-mail: dongxiangsci@163.com

*Contributed equally

Key words: Wnt2, gastric cancer, migration, invasion the mechanisms involved in the progression of gastric cancer, particularly in metastasis. Previous research has highlighted the importance of the Wnt signaling pathway, which is involved in the regulation of cell proliferation, differentiation, apoptosis and migration (4-6). Several studies have also reported that aberrant activation of Wnt signaling pathway is involved in the progression of a number of cases of gastric cancer (7). It was reported that Wnt signaling is activated in $30-50 \%$ of gastric cancer tissues and in numerous types of gastric cancer cell line (8-10). This pathway is initiated by multiple Wnt proteins, including Wnt2 and Wnt3 (11,12). Numerous members of the Wnt family of proteins, including Wnt1 and Wnt2, have been identified to be overexpressed in gastric cancer $(13,14)$. However, the precise role of this pathway in gastric cancer remains unclear.

The Wnt2 gene, located on human chromosome 7q31, has been reported to be involved in tumorigenesis and progression in numerous types of tumor, including breast cancer, pleural mesothelioma, lung cancer, colorectal cancer and pancreatic tumors (15-19). Wnt2 is expressed in human fetal lung and placenta, but almost undetectable in normal gastrointestinal tract (20). As an important member of the Wnt protein family, Wnt 2 has the ability to activate the Wnt signaling pathway in certain tumor cells. Although it has been reported that Wnt2 is frequently upregulated in primary gastric cancer (21), the role of Wnt 2 in the progression of gastric cancer is unknown, particularly the association between Wnt2 expression and clinicopathological factors. Furthermore, proliferation and metastasis of malignant gastric tumor growth are complex processes that are associated not only with the characteristics of the tumor itself but also with those of the tumor growth environment. To the best of our knowledge, none of the aforementioned studies reported whether secreted Wnt 2 affects the progression of gastric cancer via the tumor growth environment.

In the present study, we hypothesized that Wnt2 may serve a pivotal role in the progression of gastric cancer. To further investigate the role of Wnt2 in the progression of gastric cancer, the association between Wnt2 expression and clinicopathological factors was analyzed in 137 patients with gastric cancer. Subsequently, the expression of Wnt2 was evaluated in human gastric tissues and cell lines via immunohistochemical assay and western blot analysis. Then, the role of Wnt 2 in the tumor progression of gastric cancer was investigated, particularly in terms of migration and invasion. 


\section{Materials and methods}

Patients and tissue samples. The current study was approved by the Ethics Committee of Jining First People's Hospital (Jining, China). A total of 137 surgical specimens from 137 patients with gastric cancer were recruited during June 2015 to June 2016 in the Jining First People's Hospital. All patients provided signed informed consent forms. The tissue specimens were confirmed by pathological diagnosis with routine histopathological hematoxylin and eosin-staining of the specimens. The patients enrolled in the study had not received any neoadjuvant chemotherapy or radiation therapy prior to surgical treatment.

Gastric cancer was staged according to the TNM staging system (22). The enrolled patients included 32 patients at stage I, 46 at stage II, 82 at stage III and 50 at stage IV. The normal adjacent tissues were taken from $5-10 \mathrm{~cm}$ away from the tumor margin $(n=54)$. The tissue samples were dissected by a senior pathologist in the operating room, and immediately frozen in liquid nitrogen and stored at $-80^{\circ} \mathrm{C}$. The tissue samples were cut into thin sections $(5-10 \mu \mathrm{m})$, fixed in $10 \%$ formaldehyde and embedded in paraffin at $4^{\circ} \mathrm{C}$. Clinicopathological data of patients with gastric cancer were also obtained, including sex, age, tumor differentiation, tumor location, tumor size, tumor-node-metastasis (TNM) stage and lymph node status. The patient data are summarized in Table I.

Cell lines and culture conditions. Human gastric cancer cell lines, including MKN-45, SGC-7901 and BGC-823, and the human normal gastric mucosal epithelial cell line, GES-1, were obtained from Shanghai Institutes for Biological Sciences (Chinese Academy of Sciences, Shanghai, China). Cell lines were routinely maintained in RPMI-1640 medium (Gibco; Thermo Fisher Scientific, Inc., Waltham, MA, USA) containing 10\% fetal bovine serum (FBS; Abcam, Cambridge, UK) $100 \mathrm{IU} / \mathrm{ml}$ streptomycin, and $100 \mathrm{IU} / \mathrm{ml}$ penicillin in a 5\% $\mathrm{CO}_{2}$ atmosphere at $37^{\circ} \mathrm{C}$.

Plasmid construction and transfection. The Wnt2 gene (GeneBank accession no. 7472) was amplified using PCR (primers: Forward, 5'-ATGTCACCCGGATGACCAAG-3'; reverse, 5'-TCCAGAGCTTCCAGGCAGTC-3') and cloned into a pcDNA 3.1/V5-His TOPO TA vector (Invitrogen; Thermo Fisher Scientific, Inc.). The plasmids were transfected into CHO-K1 hamster cells (American Type Culture Collection, Manassas, VA, USA) using Lipofectamine 2000 (Invitrogen; Thermo Fisher Scientific, Inc.) according to the manufacturer's protocol. Stably Wnt2-expressing clones (CHO-W) were screened. CHO cells transfected with the empty vector $(\mathrm{CHO}-\mathrm{V})$ were used as the control.

Conditioned medium. $\mathrm{CHO}-\mathrm{W}$ and $\mathrm{CHO}-\mathrm{V}$ cells were cultured in Dulbecco's modified Eagle medium (DMEM; Gibco; Thermo Fisher Scientific, Inc.) containing 10\% FBS at $37^{\circ} \mathrm{C}$ until they reached $70 \%$ confluence. $\mathrm{CHO}-\mathrm{W}$ and $\mathrm{CHO}-\mathrm{V}$ cells were then harvested and continually cultured in DMEM with $3 \%$ FBS for $24 \mathrm{~h}$. Then, the culture medium was centrifuged at $1,000 \mathrm{xg}$ at $4^{\circ} \mathrm{C}$ for $30 \mathrm{~min}$ and the supernatant was collected as conditioned medium for further study, as previously described (11).
Reverse transcription-quantitative polymerase chain reaction $(R T-q P C R)$. Total RNA from the gastric cell lines was extracted using TRIzol reagent (Invitrogen; Thermo Fisher Scientific, Inc.) according to the manufacturer's protocol. RNA was converted into cDNA using a GoScript ${ }^{\mathrm{TM}}$ Reverse Transcription kit (cat. no. A5001; Promega Corporation, Madison, WI, USA) according to the manufacturer's protocol. For analysis of Wnt2 gene expression, qPCR was performed with the SYBR Green PCR core reagent kit (Applied Biosystems; Thermo Fisher Scientific, Inc.). $\beta$-actin was used as the endogenous reference. The PCR primer sequences were as follows: Wnt2 forward, 5'-CCCACAGCACATGACTTC AC-3', reverse, 5'-CTGTATCAGGGACCGAGAGG-3'; $\beta$-actin forward, 5'-GACCTCTATGCCAACACAGT-3', reverse, 5'-AGTACTTGCGCTCAGGAGGA-3', based on a previous study (23). The qPCR thermocycling conditions were as follows: $95^{\circ} \mathrm{C}$ for $10 \mathrm{~min}, 40$ cycles of $95^{\circ} \mathrm{C}$ for $15 \mathrm{sec}, 60^{\circ} \mathrm{C}$ for $30 \mathrm{sec}$ and $72^{\circ} \mathrm{C}$ for $40 \mathrm{sec}$, then $95^{\circ} \mathrm{C}$ for $60 \mathrm{sec}$, followed by dissociation curve analysis. Reverse-transcribed Human Total Reference RNA (Stratagene; Agilent Technologies, Inc., Santa Clara, CA, USA) was used to generate a standard curve. The relative expression of Wnt 2 in each cell line was analyzed using the comparative $\mathrm{Cq}$ method (24).

Western blot analysis. For western blot analysis, whole-cell extracts were prepared using RIPA buffer supplemented with protease inhibitor cocktail (Sigma-Aldrich; Merck KGaA, Darmstadt, Germany). Then, protein quantification was performed using a BCA protein assay kit. Protein lysates $(20 \mathrm{mg})$ were separated by $10 \%$ SDS-PAGE and then electrophoretically transferred onto polyvinylidene fluoride membranes. The membranes were blocked in TBST buffer containing $5 \%$ non-fat dried milk for $1 \mathrm{~h}$ at $25^{\circ} \mathrm{C}$. Then, membranes were incubated at $4^{\circ} \mathrm{C}$ overnight with monoclonal antibodies, including Rabbit anti-human Wnt2 (dilution, 1:1,000; cat. no. ab109222; Abcam) and mouse anti-human $\beta$-actin (dilution, 1:10,000; cat. no. Ab8226; Abcam). Membranes were then washed three times in TBST solution for $30 \mathrm{~min}$. Finally, membranes were incubated with horseradish peroxidase (HRP)-conjugated anti-mouse secondary antibody (dilution, 1:5,000; cat. no. A0545; Sigma-Aldrich; Merck $\mathrm{KGaA})$ and HRP-conjugated goat anti-Rabbit IgG (H\&L) antibody (dilution, 1:2,000; cat. no. AS09 602; Agrisera, Vännäs, Sweden) at $25^{\circ} \mathrm{C}$ for $1 \mathrm{~h}$.

Immunohistochemical staining. An immunohistochemical method was used to detect the protein expression of Wnt2 in gastric cancer tissue. Paraffin-embedded tissue sections (5 $\mu \mathrm{m})$ were deparaffinized, rehydrated in xylene and degradation alcohol and heated with a microwave oven in $10 \mathrm{mM}$ citrate buffer for 5-10 min for antigen retrieval. The sections were incubated with the rabbit anti-Wnt2 monoclonal antibody (dilution, 1:250) overnight at $4^{\circ} \mathrm{C}$. The slides were incubated with a HRP-conjugated goat anti-rabbit secondary antibody (dilution, 1:1,000; cat. no. ab6721; Abcam) at $37^{\circ} \mathrm{C}$ for $30 \mathrm{~min}$. The Wnt2 expression status was assessed by two examiners who were blinded to the clinicopathological data using a Zeiss 710 laser scanning confocal microscope (Zeiss AG, Oberkochen, Germany). The intensity of Wnt2 staining was evaluated using the following criteria: 0 , negative; 1 , weak staining; 2 , moderate 
Table I. Association between Wnt2 expression and clinicopathological factors of patients with gastric cancer.

\begin{tabular}{|c|c|c|c|c|}
\hline \multirow[b]{2}{*}{ Variable } & \multirow[b]{2}{*}{$\mathrm{n}$} & \multicolumn{2}{|c|}{ Wnt2 expression } & \multirow[b]{2}{*}{ P-value } \\
\hline & & Positive $(n=103)$ & Negative $(n=34)$ & \\
\hline Sex & & & & NS \\
\hline Male & 99 & 42 & 57 & \\
\hline Female & 38 & 29 & 9 & \\
\hline Age (years) & & & & NS \\
\hline$\geq 65$ & 30 & 14 & 16 & \\
\hline$<65$ & 107 & 57 & 50 & \\
\hline Tumor differentiation & & & & NS \\
\hline Well to moderate & 39 & 16 & 23 & \\
\hline Poor & 98 & 38 & 60 & \\
\hline Tumor location & & & & NS \\
\hline Gastric fundus & 8 & 5 & 3 & \\
\hline Gastric corpus & 62 & 36 & 26 & \\
\hline Pylorus & 67 & 37 & 30 & \\
\hline Tumor size $(\mathrm{cm})$ & & & & NS \\
\hline$\leq 5$ & 79 & 32 & 47 & \\
\hline$>5$ & 58 & 20 & 38 & \\
\hline TNM stage & & & & $<0.001$ \\
\hline $\mathrm{I}+\mathrm{II}$ & 60 & 18 & 42 & \\
\hline III + IV & 77 & 55 & 22 & \\
\hline Lymph node metastasis & & & & $<0.001$ \\
\hline Negative & 42 & 15 & 27 & \\
\hline Positive & 95 & 67 & 28 & \\
\hline
\end{tabular}

TNM, tumor-node-metastasis; NS, no significant difference.

staining; 3, strong staining. The percentage of positive cells was classified into five grades as follows: $0,<5 \% ; 1,5-25 \%$; 2, 25-50\%; 3, 50-75\%; 4, 75-100\%. The immunohistochemical staining score was calculated as follows: Overall score $=$ positive cell score + staining intensity score. An overall score $\leq 3$ was defined as negative, and $>3$ as positive (25).

Application of Wnt2 recombinant protein. DMEM $(\sim 1 \mathrm{ml})$ containing $2 \% \mathrm{FBS}$ was added to $5 \times 10^{4}$ cells $/ \mathrm{cm}^{2}$ gastric cancer cells in each well of a 6-well plate. Recombinant human Wnt2 protein (Abnova, Taipei, Taiwan) was added obtain concentrations of $0,50,100$ and $200 \mathrm{ng} / \mathrm{ml}$, respectively. Cells were cultured in a $5 \% \mathrm{CO}_{2}$ incubator at $37^{\circ} \mathrm{C}$ for $6 \mathrm{~h}$. Proteins were extracted from cells and western blot analysis was performed as described above to determine the optimum concentration. Subsequently, the optimum concentration of $\mathrm{Wnt} 2$ recombinant protein was applied to cells in a $5 \% \mathrm{CO}_{2}$ incubator at $37^{\circ} \mathrm{C}$ for $2,4,6,8$ and $16 \mathrm{~h}$ to determine the optimum acting time.

Cell viability assay. Cell viability was assessed by an MTT assay. SGC-7901 and BGC-823 cells were seeded at 104/well in 96-well plates, and incubated for 4 days in DMEM with $10 \%$ FBS or conditioned medium from $\mathrm{CHO}-\mathrm{W}$ or $\mathrm{CHO}-\mathrm{V}$ cells. At the end of the culture period, $50 \mu 12 \mathrm{mg} / \mathrm{ml}$ MTT was added to the medium and incubated for $3 \mathrm{~h}$ at $37^{\circ} \mathrm{C}$ with $5 \% \mathrm{CO}_{2}$. Dimethyl sulfoxide (200 $\mu \mathrm{l} /$ well) was added to dissolve the formazan crystals. The measurement was obtained at $570 \mathrm{~nm}$ using an Epoch Microplate Reader (BioTek Instruments, Inc., Winooski, VT, USA). All results are presented as a percentage compared to untreated cells.

Cell migration and invasion assays. Cell migration and invasion were analyzed using a Transwell chamber assay (Corning, Inc., Corning, NY, USA). SGC-7901 and BGC823 cells were grown with $100 \mathrm{ng} / \mathrm{ml}$ Wnt2 recombinant protein or $\mathrm{IgG}$ [negative control (NC) group] at $37^{\circ} \mathrm{C}$ for $24 \mathrm{~h}$. For the cell migration assay, a $200 \mu \mathrm{l}$ monocyte suspension of $10^{6} \mathrm{cell} / \mathrm{s} / \mathrm{ml}$ was added to the upper chamber with serum-free medium, and medium containing $10 \%$ FBS was added to the lower chamber. For the invasion assay, $10^{6}$ cells $/ \mathrm{ml}$ were resuspended in $200 \mu \mathrm{l}$ serum-free RPMI-1640 medium and placed into the upper chamber of the insert with Matrigel (BD Biosciences, Franklin Lakes, NJ, USA). Following culture with $5 \% \mathrm{CO}_{2}$ and $37^{\circ} \mathrm{C}$ for $72 \mathrm{~h}$, cells that remained attached to the upper surface of the filters were carefully removed with cotton swabs. Invaded or migrated cells were stained with $1 \%$ crystal violet for $20 \mathrm{~min}$ at room temperature and examined with an optical microscope (magnification, x200). 
Monolayer wound healing assay. Gastric cancer cells were seeded into a 6-well tissue culture dish and allowed to grow to $90 \%$ confluence in complete medium. The monolayers were wounded with a plastic pipette tip that was scratched across the plate to create a 1-mm wound, as previously described (26). The wounded monolayers were then washed four times with medium to remove cell debris and incubated for $48 \mathrm{~h}$. Cells were monitored under an optical microscope equipped with a camera at x200 magnification.

Statistical analysis. All analyses were performed using GraphPad Prism 6 software (GraphPad Software, Inc., La Jolla, CA, USA). Continuous variable values were expressed as the mean \pm standard deviation. Student's t-test or analysis of variance (ANOVA) for unpaired data were used to compare mean values. Tukey's post-hoc test was used with ANOVA. The association of risk factors with the prognosis of patients with gastric cancer was evaluated by $\chi^{2}$ analysis. All tests were two-sided, and $\mathrm{P}<0.05$ was considered to indicate a statistically significant difference. Error bars indicated standard deviation.

\section{Results}

Associations between Wnt2 expression and clinicopathological factors of patients with gastric cancer. Clinicopathological characteristics and their associations with Wnt2 expression are presented in Table I. In the current study, there were 99 males and 38 females, and the age at diagnosis ranged from 27 to 80 years. Tumor differentiation was classified into two levels, including well to moderate and poor. The results suggested that Wnt2 expression was significantly associated with advanced stages of gastric cancer (III + IV) rather than early stages (I + II; P<0.001). Furthermore, Wnt2 expression was significantly associated with lymph node metastasis $(\mathrm{P}<0.001)$. However, Wnt2 expression was not associated with sex, age, tumor differentiation, tumor location or tumor size.

Expression of Wnt2 in human gastric tissues and cell lines. To further understand the clinicopathological significance of Wnt2 in gastric cancer, Wnt2 expression level was detected in gastric cancer samples and adjacent normal gastric tissues by immunohistochemical assay and western blot analysis. As indicated in Fig. 1A, the immunostaining of Wnt2 protein was different between non-tumor gastric mucosa and gastric cancer tissue. Wnt2 expression was positive in gastric cancer tissue, and negative in non-tumor gastric mucosa. The level of Wnt2 in cancer samples was significantly higher compared with corresponding adjacent noncancerous tissues (Fig. 1B).

To explore the role of Wnt2 in gastric cancer progression, the expression of Wnt2 in human gastric cell lines was detected, including MKN-45, GES-1, SGC-7901 and BGC-823. As indicated in Fig. 2A, RT-qPCR analysis of Wnt2 mRNA revealed that the transcription level of Wnt2 in cancer cell lines, particularly in SGC-7901 and BGC-823, was markedly higher compared with the normal gastric cell line. Notably, transcription levels of Wnt2 in SGC-7901 and BGC-823 were also markedly higher compared with MKN-45. Western blotting results revealed that Wnt2 expression in SGC-7901 and BGC-823 cells was markedly higher increased compared with the normal gastric cell line (Fig. 2B).
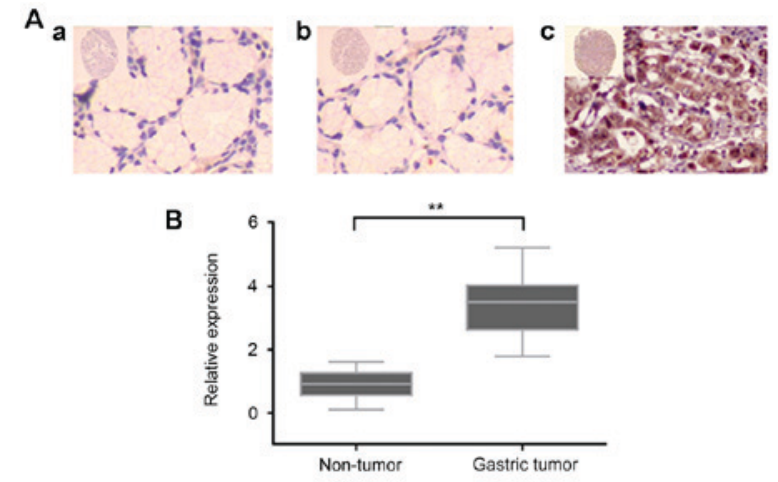

Figure 1. Immunohistochemical staining of human gastric tissues. (A) Immunostaining of Wnt 2 protein in human gastric tissues (magnification of the inset, x20; main image, $x 200$ ). (Aa) Negative Wnt2 expression in normal gastric tissue. (Ab) Negative Wnt2 expression in non-tumor gastric mucosa. (Ac) Positive Wnt2 expression in gastric cancer tissue. (B) Expression level of Wnt2 protein in gastric cancer tissues was significantly higher compared with adjacent non-cancerous tissues. ${ }^{* *} \mathrm{P}<0.001$.
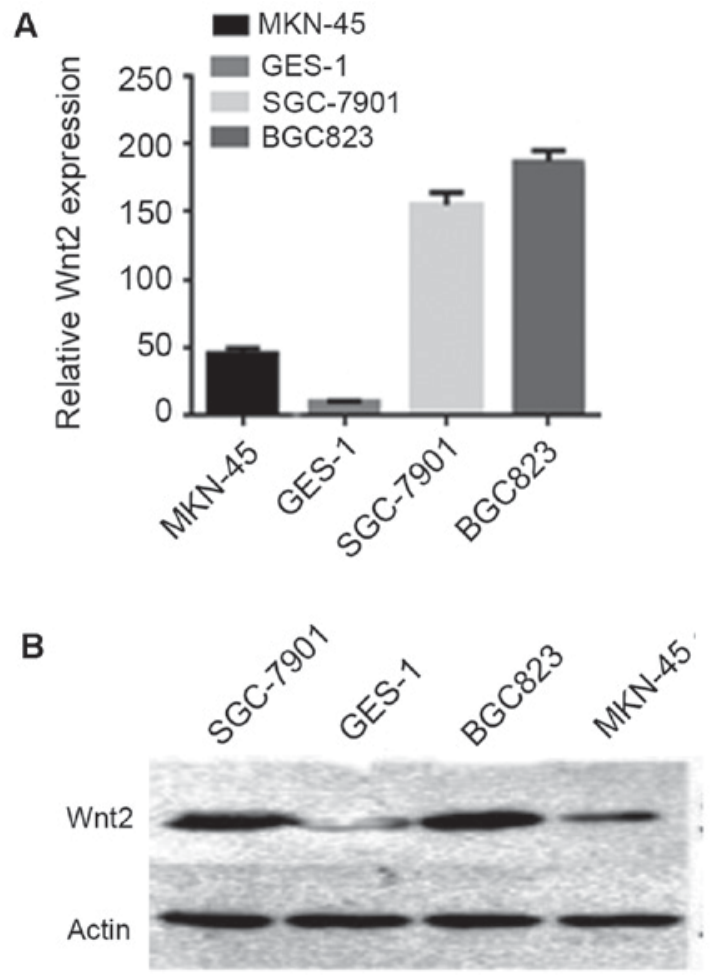

Figure 2. Expression of Wnt2 in human gastric cell lines. (A) Reverse transcription-quantitative polymerase chain reaction analysis of Wnt 2 mRNA in four gastric cancer cell lines and a noncancerous cell line, GES-1. (B) Western blot analysis of Wnt 2 protein in four gastric cancer cell lines and GES-1. The 40-kDa band was detected by anti-Wnt 2 antibody (upper row), and the 42-kDa band was detected by anti-actin antibody (lower row) as the loading control.

Establishment of secreted Wnt 2 conditioned medium. To investigate the effect of Wnt 2 on gastric cancer cells, an in vitro Wnt 2 secreting system was established using $\mathrm{CHO}$ cells. A Wnt2 expression plasmid was stably transfected into $\mathrm{CHO}$ cells (CHO-W), and empty vector-transfected $\mathrm{CHO}$ cells $(\mathrm{CHO}-\mathrm{V})$. The conditioned medium was collected after $24 \mathrm{~h}$ of culture in 3\% FBS, and the ectopic expression of Wnt2 in $\mathrm{CHO}$ cells was validated at the protein level (Fig. 3A and B). 
A

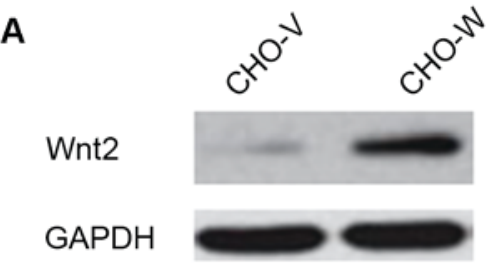

C

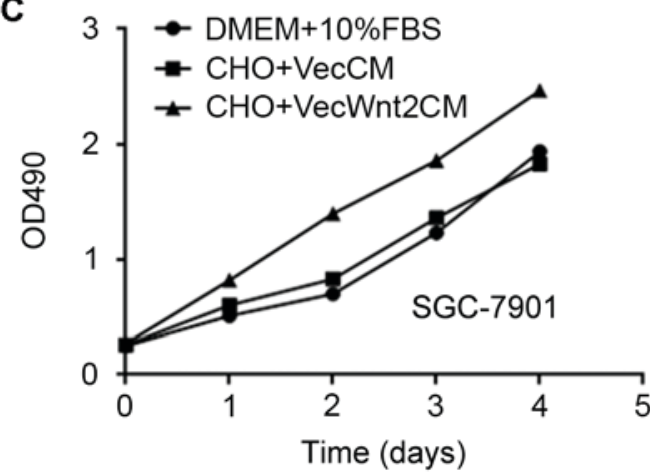

B

Wnt2 $\mid \begin{aligned} & \text { Medium } \\ & \text { Lysate }\end{aligned}$

GAPDH

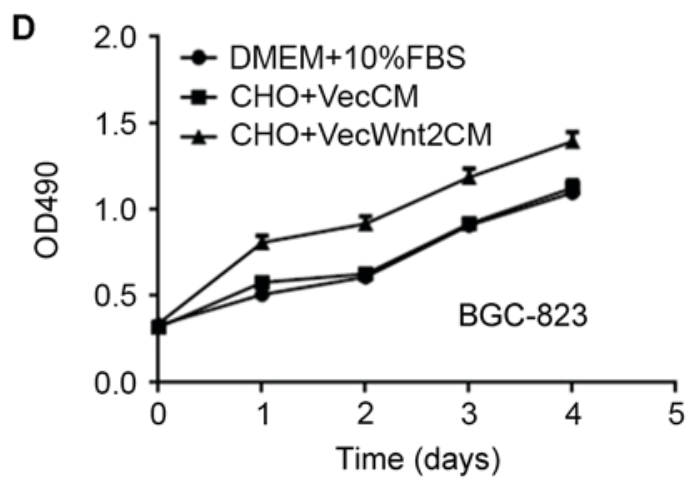

Figure 3. Secreted Wnt2 promotes cell proliferation in gastric cancer cell lines. A plasmid containing Wnt2 was stably transfected into CHO cells and CM containing secreted Wnt2 was collected for further study. (A) Expression of Wnt 2 in CHO-W was confirmed by western blot analysis. (B) Quantification of the western blot analysis indicated that Wnt 2 protein could be detected in $\mathrm{CHO}-\mathrm{W}$ and the $\mathrm{CM}$ of $\mathrm{CHO}-\mathrm{W}$. Effects of normal growth media (DMEM $+10 \%$ fetal bovine serum), VecCM or VecWnt2CM on the growth of gastric cancer cells (C) SGC-7901 and (D) BGC823 were compared by an MTT assay. Data are presented as the mean \pm standard deviation of three independent experiments. $\mathrm{CM}$, conditioned medium; $\mathrm{CHO}-\mathrm{W}$, Wnt2-transfected $\mathrm{CHO}$ cells; $\mathrm{CHO}-\mathrm{V}$, empty vector-transfected CHO cells; DMEM, Dulbecco's modified Eagle's medium; VecCM, control CM; VecWnt2CM, CHO-Wnt2 CM; OD, optical density.

The results indicated that Wnt 2 protein could be detected in conditioned medium from $\mathrm{CHO}-\mathrm{W}$.

Wnt2 promotes cell proliferation in gastric cancer cell lines. To analyze the effect of Wnt2 on gastric tumor cell proliferation, SGC-7901 and BGC-823 cells were incubated for 4 days in DMEM with $10 \%$ FBS or in conditioned medium from $\mathrm{CHO}-\mathrm{W}$ or $\mathrm{CHO}-\mathrm{V}$. The cell proliferation (MTT) assay indicated that the cell growth rate of SGC-7901 was markedly higher in cells cultured with conditioned medium from $\mathrm{CHO}-\mathrm{W}$ compared with cells cultured with conditioned medium from CHO-V (Fig. 3B). Similar results were observed in the BGC-823 cell line (Fig. 3C and D).

Wht2 enhances cell migration and invasion. As a previous study reported that the positive expression of Wnt 2 was closely associated with gastric cancer metastasis (14), the effects of Wnt2 on SGC-7901 and BGC-823 motility and invasiveness were evaluated by Transwell and wound healing assays in the present study. The results of the Transwell assay demonstrated that the recombinant protein Wnt2 increased the invasiveness of gastric cancer cells. Following $24 \mathrm{~h}$ of culture with recombinant Wnt2, the number of gastric cancer cells that invaded into the lower chamber markedly increased. The same trend was also observed in the migration assay ( $\mathrm{P}<0.05$; Fig. $4 \mathrm{~A}$ and $\mathrm{B})$. Consistent results were also observed in SGC-7901 cell lines ( $\mathrm{P}<0.05$; Fig. 4C and D).

The wound healing assay demonstrated that Wnt 2 protein facilitated the migration of gastric cancer cells. At $48 \mathrm{~h}$ after scratching the cell surface, the distance from the edge of the wound was measured (Fig. 5). Gastric cancer cells (SGC-7901 and BGC823) cultured in Wnt2 recombinant protein exhibited significantly increased migration into the wound areas compared with the control groups $(\mathrm{P}<0.05)$.

\section{Discussion}

The Wnt signaling pathway has been identified as one of the key signaling pathways in the process of tumorigenesis (26). Wnt proteins, including Wnt 2 and Wnt3, initiate the Wnt signaling pathway $(11,12)$. In particular, Wnt 2 has been reported to activate the Wnt signaling pathway (27). Additionally, the Wnt signaling pathway plays a pivotal role in the regulation of cell proliferation, differentiation, apoptosis and migration $(4,5)$. As it has been reported that Wnt 2 is frequently upregulated in primary gastric cancer (21), the current study focused on whether Wnt 2 plays a role in the progression of gastric cancer, particularly in cell migration and invasion. In the present study, the associations between Wnt2 expression and clinicopathological factors of patients with gastric cancer were evaluated. Wnt 2 expression level was detected in gastric cancer samples and adjacent normal gastric tissues by immunohistochemical assay and western blot analysis. The results indicated that Wnt 2 expression in gastric cancer tissues was significantly associated with higher TNM stage, which suggests that Wnt2 serves a function in the progression of gastric cancer.

In the current study, Wnt 2 expression was evaluated in four gastric cancer cell lines in comparison with the GES-1 cell line. RT-qPCR analysis of Wnt 2 mRNA revealed that the transcription levels of Wnt 2 in cancer cell lines, particularly SGC-7901 and BGC823, were markedly higher compared with a normal gastric cell line. Wnt2 expression in MKN-45 cells 
A
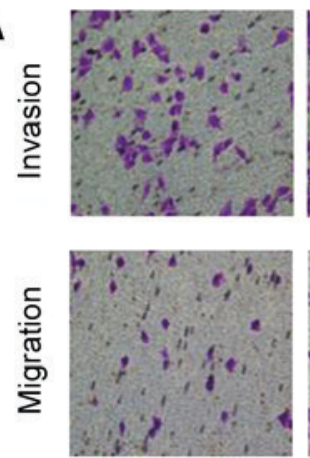

C
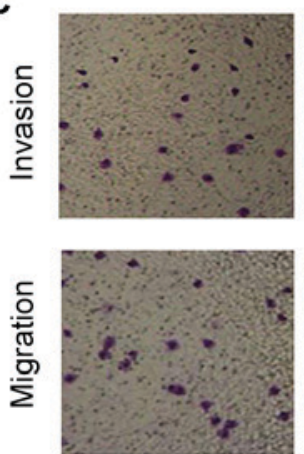
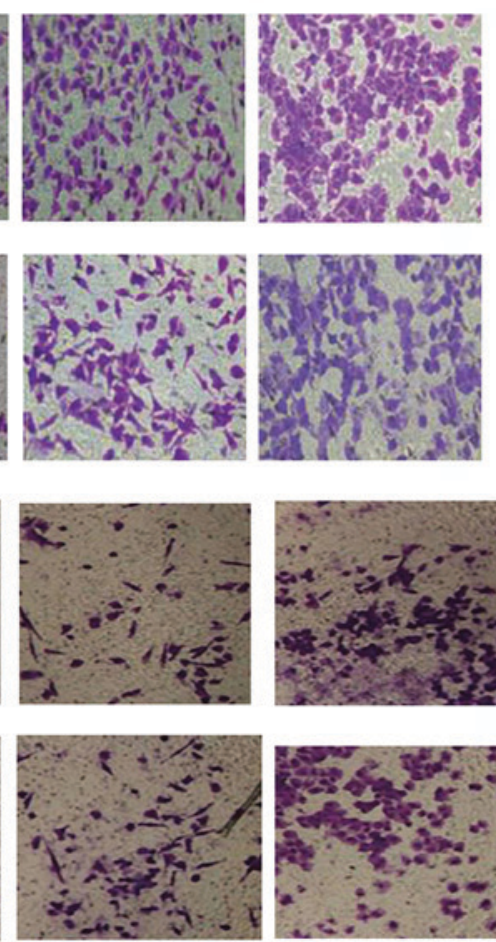
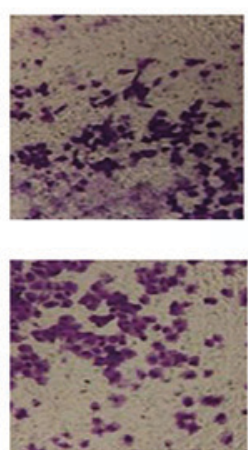

B
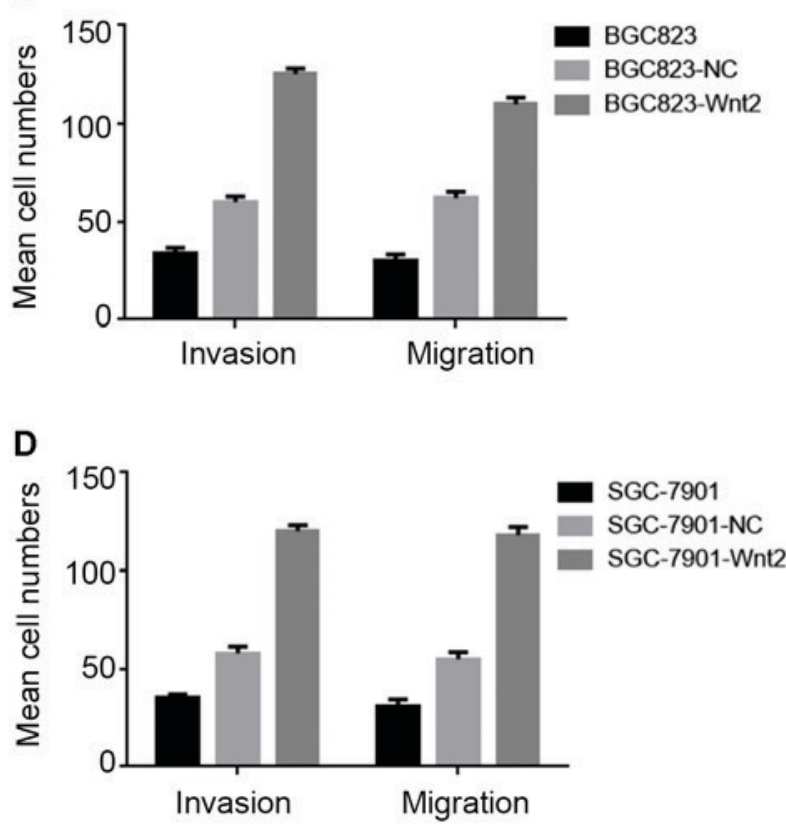

Figure 4. Recombinant protein Wnt2 promotes the migration and invasion of gastric cells in vitro. (A) Transwell assay for BGC823 cells. Images indicate cells that travelled through the micropore membrane with or without Matrigel. (B) Histograms indicate the number of BGC823 cells that migrated or invaded through the chamber. (C) Transwell assay for SGC-7901 cells. Images indicate cells that travelled through the micropore membrane with or without Matrigel. (D) Histograms indicate the number of SGC-7901 cells that migrated or invaded through the chamber. Magnification, x200. NC, negative control.
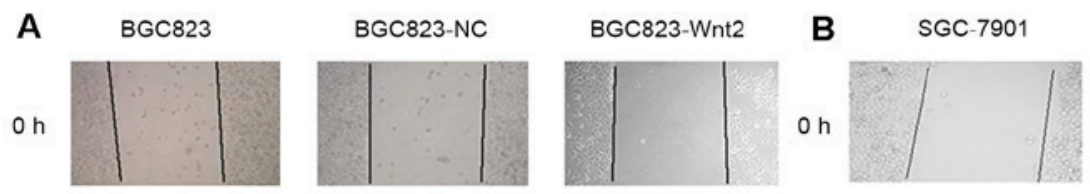

SGC-7901NC

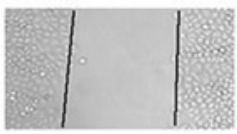

SGC-7901Wnt2

$48 \mathrm{~h}$
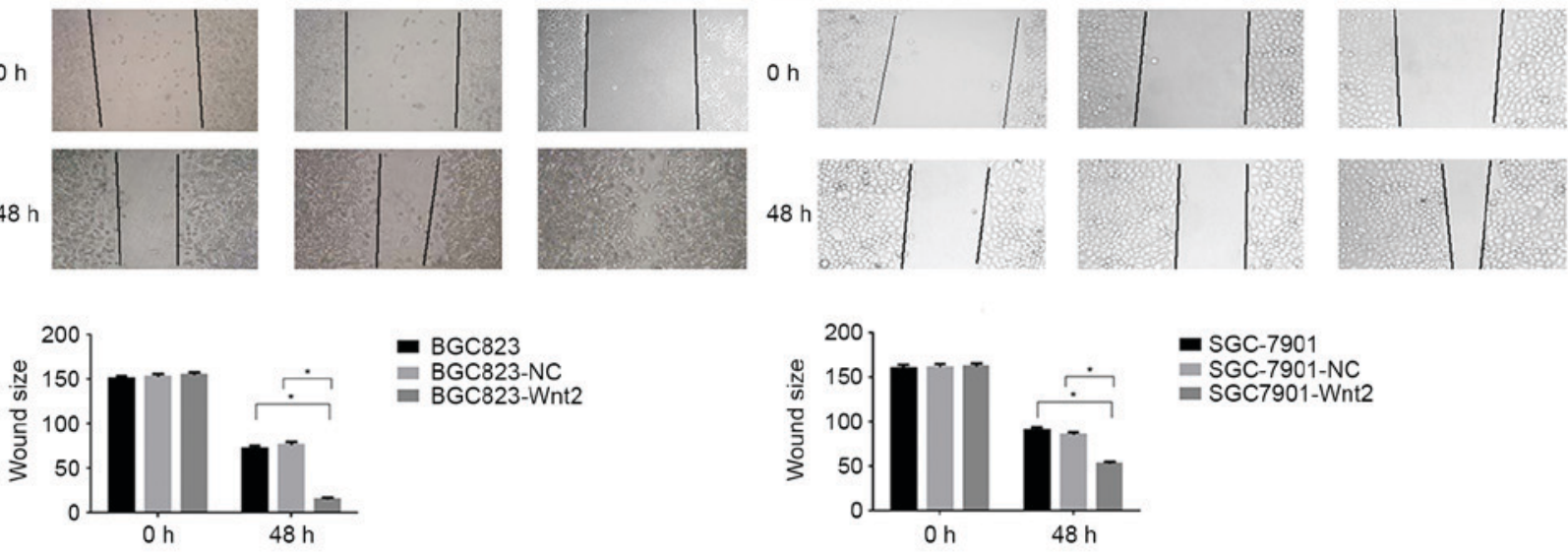

- SGC-7901

= SGC-7901-NC

․ SGC7901-Wnt2

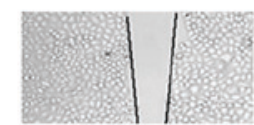

Figure 5. Effects of Wnt2 on wound healing in gastric cancer cells. Wound healing assay with (A) BGC823 and (B) gastric cancer cells. Microscopic observations were recorded at 0 and $48 \mathrm{~h}$ after scratching the cell surface. Representative images from each experiment are shown. Magnification, $\mathrm{x} 100$. ${ }^{*} \mathrm{P}<0.05$. NC, negative control.

was less than that of SGC-7901 and BGC823, indicating that Wnt2 expression may be altered across all gastric cancer cell lines. Furthermore, western blot results revealed that Wnt2 expression in SGC-7901 and BGC823 was markedly higher compared with the normal gastric cell line. Since BGC-823 and SGC-7901 cells have malignant characteristics, Wnt2 may serve a function in the development or maintenance of a malignant phenotype (7). Therefore, BGC-823 and SGC-7901 were selected for subsequent experiments. Using the secreted Wnt2 conditioned medium, an MTT assay indicated that secreted
Wnt 2 promoted cell proliferation. However, the mechanism by which Wnt 2 affects proliferation in gastric cancer is still unclear, and requires further investigation.

Another notable finding was that Wnt 2 promotes metastasis of gastric cancer, according to the results of the Transwell and wound healing assays. It was previously reported that the Wnt signaling pathway induces epithelial-mesenchymal transition (EMT) in tumors $(28,29)$. Additionally, several studies have demonstrated that EMT is able to promote the metastasis of cancer, as it may change adhesive properties and endow cells 
with migratory and invasive properties (28). Furthermore, it has been reported that EMT plays an important role in the metastasis of gastric cancer (29). In summary, Wnt2 may promote cell motility and invasiveness via activating EMT of gastric cancer. However, the molecular processes underlying Wnt2 still require further elucidation via direct experiments.

During metastatic progression, tumor cells may form a microenvironment that facilitates tumor cells migration and invasion (30). It has been reported that local regulation by Wnt signals could affect tissue microenvironments in vivo and subsequently affect cell differentiation, cell migration and adhesion (31). In the wound healing assay in the current study, secreted Wnt 2 promoted the migration of gastric cancer cells. This suggests that secreted Wnt2, which may be present in the microenvironment of gastric tumors, could promote the migration and invasion abilities of gastric cancer cells. Therefore, Wnt 2 may be a potential target in improving the status of the microenvironment and gastric cancer cells. However, further investigation is required into the detailed mechanisms of secreted Wnt 2 in metastasis, particularly in the microenvironment of gastric tumors.

In summary, the present results validated the hypothesis that Wnt 2 plays a critical role in the progression of gastric cancer, via mediating signaling between cancer cells and the stromal environment. Based on the current findings, it is also suggested that Wnt2 may be considered as a promising target for the treatment of gastric cancer. Blocking Wnt 2 function may be effective in preventing tumor cell metastasis. However, it still remains unclear how Wnt 2 protein directly affects Wnt signaling in gastric cancer, and therefore further studies should be conducted to investigate the molecular mechanisms of Wnt2 in the Wnt signaling pathway.

\section{Acknowledgements}

The authors would like to thank Dr Xuerong Li (Zhongshan School of Medicine, Sun Yat-Sen University) for valuable technical assistance in cell culture, and Dr Xinbing Yu (Zhongshan School of Medicine, Sun Yat-Sen University) for expert technical assistance.

\section{Funding}

No funding was received.

\section{Availability of data and materials}

The datasets used and/or analyzed during the current study are available from the corresponding author on reasonable request.

\section{Authors' contributions}

ZZ conceived of the study. ZZ and JW performed the experiments. XD supervised the study. XD analyzed the data and all authors contributed to the final manuscript.

\section{Ethics approval and consent to participate}

The present study was approved by the Ethics Committee of Jining First People's Hospital (Jining, China). The patients provided written informed consent for the use of their data.

\section{Consent for publication}

Not applicable.

\section{Competing interests}

The authors declare that they have no competing interests.

\section{References}

1. Torre LA, Bray F, Siegel RL, Ferlay J, Lortet-Tieulent J and Jemal A: Global cancer statistics, 2012. CA Cancer J Clin 65: 87-108, 2015.

2. Chen W, Zheng R, Zeng H, Zhang S and He J: Annual report on status of cancer in China, 2011. Chin J Cancer Res 27: 2-12, 2015.

3. Hu L, Duan YT, Li JF, Su LP, Yan M, Zhu ZG, Liu BY and Yang QM: Biglycan enhances gastric cancer invasion by activating FAK signaling pathway. Oncotarget 5: 1885-1896, 2014.

4. Clevers $\mathrm{H}$ and Nusse R: Wnt/ $\beta$-catenin signaling and disease. Cell 149: 1192-1205, 2012.

5. Baarsma HA, Königshoff M and Gosens R: The WNT signaling pathway from ligand secretion to gene transcription: Molecular mechanisms and pharmacological targets. Pharmacol Ther 138: 66-83, 2013.

6. Polakis P: Wnt signaling in cancer. Cold Spring Harb Perspect Biol 4: pii: a008052, 2012.

7. Chiurillo MA: Role of the Wnt/ $\beta$-catenin pathway in gastric cancer: An in-depth literature review. World J Exp Med 5: 84-102, 2015.

8. Ooi CH, Ivanova T, Wu J, Lee M, Tan IB, Tao J, Ward L, Koo JH, Gopalakrishnan V, Zhu Y, et al: Oncogenic pathway combinations predict clinical prognosis in gastric cancer. PLoS Genet 5: e1000676, 2009.

9. Clements WM, Wang J, Sarnaik A, Kim OJ, MacDonald J, Fenoglio-Preiser C, Groden J and Lowy AM: Beta-catenin mutation is a frequent cause of Wnt pathway activation in gastric cancer. Cancer Res 62: 3503-3506, 2002.

10. Ikenoue T, Ijichi H, Kato N, Kanai F, Masaki T, Rengifo W, Okamoto M, Matsumura M, Kawabe T, Shiratori Y and Omata M: Analysis of the beta-catenin/T cell factor signaling pathway in 36 gastrointestinal and liver cancer cells. Jpn J Cancer Res 93: 1213-1220, 2002.

11. Fu L, Zhang C, Zhang LY, Dong SS, Lu LH, Chen J, Dai Y, Li Y, Kong KL, Kwong DL and Guan XY: Wnt2 secreted by tumour fibroblasts promotes tumour progression in oesophageal cancer by activation of the Wnt/ $\beta$-catenin signalling pathway. Gut 60 : 1635-1643, 2011.

12. Wu Y, Ginther C, Kim J, Mosher N, Chung S, Slamon D and Vadgama JV: Expression of Wnt 3 activates Wnt $/ \beta$-catenin pathway and promotes EMT-like phenotype in trastuzumab-resistant HER2-overexpressing breast cancer cells. Mol Cancer Res 10: 1597-1606, 2012.

13. Mao J, Fan S, Ma W, Fan P, Wang B, Zhang J, Wang H, Tang B, Zhang Q, Yu X, et al: Roles of Wnt/ $\beta$-catenin signaling in the gastric cancer stem cells proliferation and salinomycin treatment. Cell Death Dis 5: e1039, 2014.

14. Cheng XX, Wang ZC, Chen XY, Sun Y, Kong QY, Liu J and $\mathrm{Li} \mathrm{H}$ : Correlation of Wnt-2 expression and beta-catenin intracellular accumulation in Chinese gastric cancers: Relevance with tumour dissemination. Cancer Lett 223: 339-347, 2005.

15. Vider BZ, Zimber A, Chastre E, Prevot S, Gespach C, Estlein D, Wolloch Y, Tronick SR, Gazit A and Yaniv A: Evidence for the involvement of the Wnt 2 gene in human colorectal cancer. Oncogene 12: 153-158, 1996.

16. Watanabe O, Imamura H, Shimizu T, Kinoshita J, Okabe T, Hirano A, Yoshimatsu K, Konno S, Aiba M and Ogawa K: Expression of twist and wnt in human breast cancer. Anticancer Res 24: 3851-3856, 2004.

17. Jiang H, Li Q, He C, Li F, Sheng H, Shen X, Zhang X, Zhu S, Chen $\mathrm{H}$, Chen X, et al: Activation of the Wnt pathway through Wnt2 promotes metastasis in pancreatic cancer. Am J Cancer Res 4: 537-544, 2014.

18. Mazieres J, You L, He B, Xu Z, Twogood S, Lee AY, Reguart N, Batra S, Mikami I and Jablons DM: Wnt2 as a new therapeutic target in malignant pleural mesothelioma. Int J Cancer 117: 326-332, 2005 . 
19. Valkenburg KC, Graveel CR, Zylstra-Diegel CR, Zhong Z and Williams BO: Wnt/ $\beta$-catenin signaling in normal and cancer stem cells. Cancers (Basel) 3: 2050-2079, 2011.

20. Katoh M: WNT2 and human gastrointestinal cancer (review). Int J Mol Med 12: 811-816, 2003.

21. Katoh M: Frequent up-regulation of WNT2 in primary gastric cancer and colorectal cancer. Int J Oncol 19: 1003-1007, 2001.

22. In H, Solsky I, Palis B, Langdon-Embry M, Ajani J and Sano T: Validation of the 8th edition of the AJCC TNM staging system for gastric cancer using the national cancer database. Ann Surg Oncol 24: 3683-3691, 2017.

23. Huang C, Ma R, Xu Y, Li N, Li Z, Yue J, Li H, Guo Y and Qi D: Wnt2 promotes non-small cell lung cancer progression by activating WNT/3-catenin pathway. Am J Cancer Res 5: 1032-1046, 2015.

24. Schmittgen TD and Livak KJ: Analyzing real-time PCR data by the comparative C(T) method. Nat Protoc 3: 1101-1108, 2008.

25. Xu Y, Li H, Huang C, Zhao T, Zhang H, Zheng C, Ren H and Hao J: Wnt2 protein plays a role in the progression of pancreatic cancer promoted by pancreatic stellate cells. Med Oncol 32: 97, 2015.

26. Jeong HW, Nam JO and Kim IS: The COOH-terminal end of R-Ras alters the motility and morphology of breast epithelial cells through Rho/Rho-kinase. Cancer Res 65: 507-515, 2005.
27. Cheng XX, Wang ZC, Chen XY, Sun Y, Kong QY, Liu J, Gao X, Guan HW and Li H: Frequent loss of membranous E-cadherin in gastric cancers: A cross-talk with Wnt in determining the fate of beta-catenin. Clin Exp Metastasis 22: 85-93, 2005.

28. Yilmaz M and Christofori G: EMT, the cytoskeleton, and cancer cell invasion. Cancer Metastasis Rev 28: 15-33, 2009.

29. Peng Z, Wang CX, Fang EH, Wang GB and Tong Q: Role of epithelial-mesenchymal transition in gastric cancer initiation and progression. World J Gastroenterol 20: 5403-5410, 2014.

30. Valastyan S and Weinberg RA: Tumor metastasis: Molecular insights and evolving paradigms. Cell 147: 275-292, 2011.

31. Klapholz-Brown Z, Walmsley GG, Nusse YM, Nusse R and Brown PO: Transcriptional program induced by Wnt protein in human fibroblasts suggests mechanisms for cell cooperativity in defining tissue microenvironments. PLoS One 2: e945, 2007. 